\title{
Fusion neutronics experiments
}

\author{
K. Seidel ${ }^{*}, 1$, M. Angelone ${ }^{2}$, P. Batistoni ${ }^{2}$, U. Fischer ${ }^{3}$, H. Freiesleben ${ }^{1}$, A. Klix ${ }^{1}$, D. \\ Leichtle $^{3}$, M. Pillon ${ }^{2}$, E. Pönitz ${ }^{1+}$, I. Schäfer ${ }^{4}$, S. Unholzer ${ }^{1}$ \\ ${ }^{I}$ TU Dresden, Institut für Kern- und Teilchenphysik, D-01062 Dresden, Germany \\ ${ }^{2}$ ENEA Frascati, Settore Fusione, I-00044 Frascati, Italy \\ ${ }^{3}$ FZ Karlsruhe, Institut fürReaktorsicherheit, D-76021 Karlsruhe, Germany \\ ${ }^{4}$ VKTA Rossendorf, D-01314 Dresden, Germany \\ E-mail: seidel@physik.phy.tu-dresden.de
}

\begin{abstract}
The nuclear design of fusion devices is based on neutronics calculations. The neutron and photon flux spectra are calculated with 3D neutron-photon transport codes, and the nuclear responses are obtained by convolution with the related nuclear data. These computational tools and data need to be validated through mock-up and benchmark experiments.

Typical experiments, carried out in the frame of the European Fusion Technology Programme, are discussed, in particular a bulk shield experiment on a mock-up of the inboard shield of the International Thermonuclear Experimental Reactor (ITER), benchmarks of the transport and of the activation data of tungsten and measurements on a neutronics mock-up of a test blanket module for ITER.
\end{abstract}

International Workshop on Fast Neutron Detectors and Applications University of Cape Town, South Africa

April 3 - 6, 2006

\footnotetext{
* Presenting author

+ Present address: Physikalisch-Technische Bundesanstalt Braunschweig, D-38116 Braunschweig, Germany
} 


\section{Introduction}

With the construction of the International Thermonuclear Experimental Reactor (ITER), research and development in the field of nuclear fusion enter a qualitatively new stage. The aim of the ITER experiments is the demonstration of the scientific and technological feasibility of fusion as an energy source and the demonstration of the safety and environmental potential of fusion power [1].

By the fusion reaction $\mathrm{d}+\mathrm{t} \rightarrow \alpha+\mathrm{n}$ an energy of $\mathrm{E}_{\mathrm{Q}}=17.6 \mathrm{MeV}$ is produced in a magnetically confined plasma of the TOKAMAK type. This energy appears as kinetic energy of the $\alpha$-particles $(3.5 \mathrm{MeV})$ and of the neutrons $(14.1 \mathrm{MeV})$. Whereas the $\alpha$-particles heat the plasma, the neutrons leave it, and their energy is converted into heat in the plasma- facing components of the reactor, i. e. in the first wall, the blanket, the divertor and the vacuum vessel. By the interactions of the neutrons with the nuclei of the reactor materials, $\gamma$-rays and radiation damage are produced, the materials are activated and the tritium fuel has to be produced by neutron reactions on lithium. This is the field of fusion neutronics.

The nuclear design of a fusion reactor is based on the data provided by neutronics calculations. The neutron and $\gamma$-ray flux spectra are calculated with 3D neutron-photon transport codes, and the nuclear responses are obtained by convolution with the related nuclear data. These computational tools and the data need to be validated through mock-up and benchmark experiments. In the paper a mock-up experiment of the ITER inboard shield (chapter 2) is presented. As examples of benchmark experiments, one directed to the transport data of tungsten (chapter 3) and one to the activation data of W (chapter 4) are discussed. A test blanket module for tritium breeding at ITER was investigated by a neutronics mock-up as well (chapter $5)$.

\section{Bulk shield experiment}

In the ITER device, the neutron and $\gamma$-ray fluxes have to be sufficiently attenuated over a short distance between the plasma chamber and the superconducting coils. Accordingly the aim of the bulk shield experiment was the verification of the shielding performance of the ITER design [2]. The mock-up is shown in Fig. 1.

The assembly was irradiated with D-T neutrons at the Frascati Neutron Generator, and measurements were carried out at several positions along the central axis. Reaction rates were measured with activation foils sensitive to thermal or fast neutrons with different thresholds. Fission rates were determined with micro fission chambers. The nuclear heating was measured with both thermoluminescence detectors and a silicon micro-sensor. The neutron and $\gamma$-ray flux spectra were simultaneously determined at the positions A0 and B0 with a NE 213 pulse-height spectrometer developed at PTB Braunschweig [3]. 
First wall/ Blanket /Vacuum vessel /TF coil

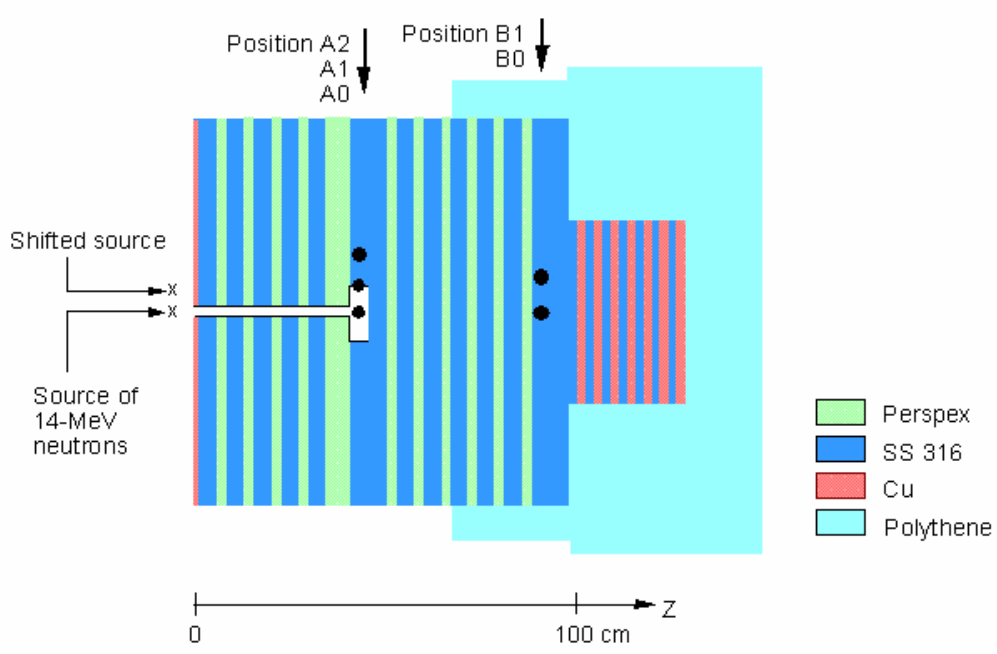

Figure 1. Vertical cut through the mock-up assembly. The steel and perspex plates of the blanket and of the vacuum vessel mock-up had dimensions of $1 \mathrm{~m} \mathrm{x}$ $1 \mathrm{~m}$. In the bulk shield experiment, the channel and the cavity in the blanket part was filled with material.

All the experimental data were compared with the results of calculations using the ITER design tools, i. e. the 3D Monte Carlo code MCNP and the Fusion Evaluated Nuclear Data Library FENDL-2. As the flux spectra have a key function in the nuclear design, they are presented in this paper (Fig. 2).
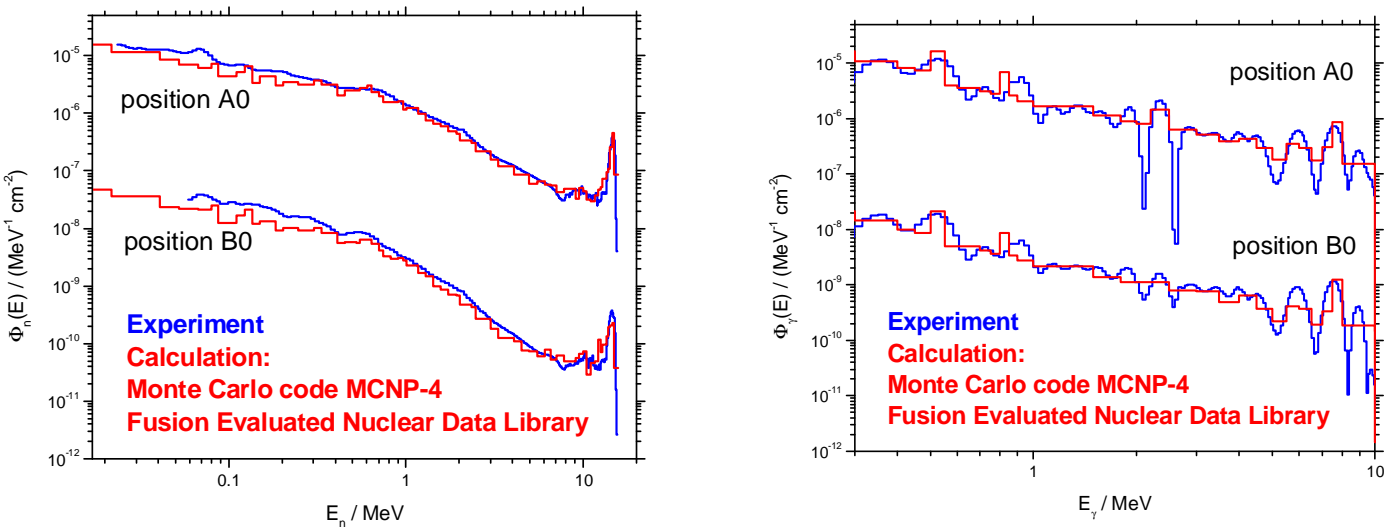

Figure 2. Comparison of the measured neutron (left hand) and $\gamma$-ray (right hand) fluence spectra normalized to one source neutron with the calculated ones. 
Similar tendencies in the comparison of the measured with the corresponding calculated values were consistently found also for the other nuclear responses. It was concluded that the inboard shielding system of ITER is correctly predicted within $\pm 30 \%$. Therefore, the safety margins of the design could be reduced significantly, resulting in a total thickness of $82 \mathrm{~cm}$ for the present ITER-FEAT version compared to a thickness of $94 \mathrm{~cm}$ for the ITER-FDR version. The reduction of the fusion power of ITER-FEAT to about half of the value of ITER-FDR had allowed a reduction of the thickness by $5 \mathrm{~cm}$ only [4].

Mock-up experiments were also carried out for validating the design calculations for gaps and channels which cause streaming in the ITER shield [5] (Fig. 1) and for validating the calculated shut-down dose rates due to activations in the shield [6].

\section{Benchmark experiment of the tungsten transport data}

Tungsten is used for the divertor of ITER and it is an alloying constituent of several structural materials of fusion devices. In order to achieve a high sensitivity to the neutron and $\gamma$ ray transport data, a W assembly of simple geometry and of a thickness of several mean free path lengths (mfp) for $14 \mathrm{MeV}$ neutrons was investigated [7]. As outlined in Fig. 3, a W block of a thickness of $49 \mathrm{~cm}$ (corresponding to $16 \mathrm{mfp}$; and of width and height of $47 \mathrm{~cm}$ ) was irradiated with D-T neutrons at the Frascati Neutron Generator. At the positions P1-P4 flux spectra were measured with a NE 213 spectrometer [3]. Reaction rates with activation foils and nuclear heating with TLD were determined as well.

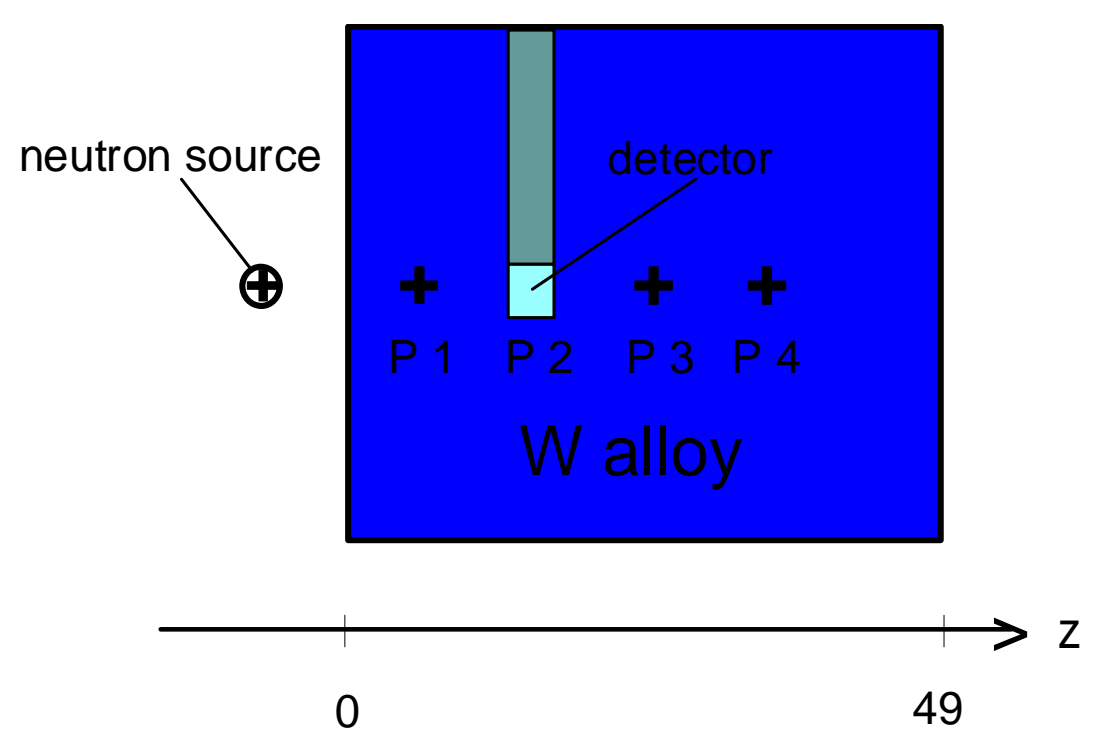

Figure 3. Vertical cut through the benchmark assembly. The $\mathrm{W}$ block had a thickness of $49 \mathrm{~cm}$; height and width were 47 $\mathrm{cm}$. 
The results of the spectra measurements for one of the detector positions are compared in Fig. 4 with calculations.
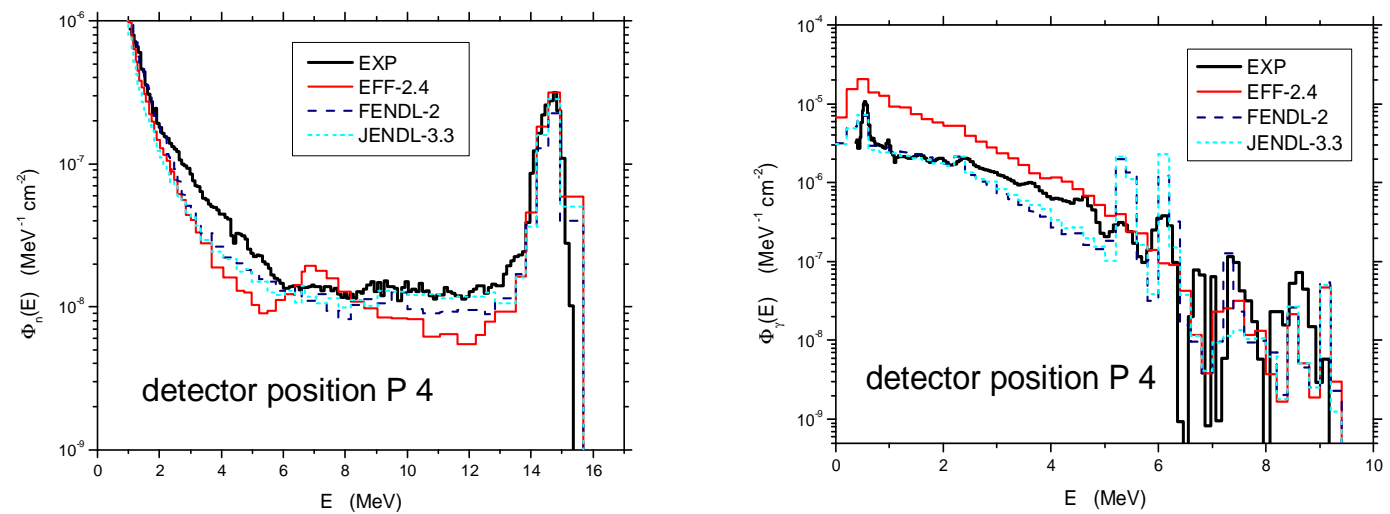

Figure 4. Comparison of the measured neutron (left hand) and $\gamma$-ray (right hand) fluence spectra normalized to one source neutron for position P4 with the calculated ones, using data of the three libraries indicated.

As the neutron flux for $\mathrm{E}>2 \mathrm{MeV}$ is underestimated with data from the FENDL-2 library, calculations were also carried out with data from the European Fusion File (EFF-2.4) and from the Japanese Evaluated Nuclear Data Library (JENDL-3.3). With EFF-2.4 data, the neutron flux spectrum shows an artificial structure at $\mathrm{E}=4-13 \mathrm{MeV}$, and the $\gamma$-ray flux is overestimated by a factor of 3-4, as consistently found in the TLD measurements. Discrepancies appear also for the $\gamma$-rays with energies corresponding to the neutron binding energies of $\mathrm{W}$ isotopes for FENDL-2 and JENDL-3.3 data. As none of the libraries gives a satisfying description of the flux spectra a re-evaluation of the EFF data for the next version EFF-3 was started with recent experimental data and improved reaction models.

Similar benchmark experiments of the neutron transport data were performed for $\mathrm{Fe}[8]$ and $\mathrm{SiC}[9]$.

\section{Benchmark experiment of the tungsten activation data}

Activation in fusion reactor materials is mainly produced by thermal neutrons where some capture cross sections are very large and by the $14 \mathrm{MeV}$ fusion peak neutrons where many different reaction channels are open. A benchmark experiment for the activation by the fusion peak neutrons has a simple geometry (Fig. 5). Small samples of a mass of the order of $1 \mathrm{~g}$ are irradiated at a D-T neutron generator; in the case of $\mathrm{W}$ at the high-intensity generator SNEG-13 in Sergiev Posad [10]. The induced $\gamma$-activities are determined with an HPGe-spectrometer after the irradiation. 


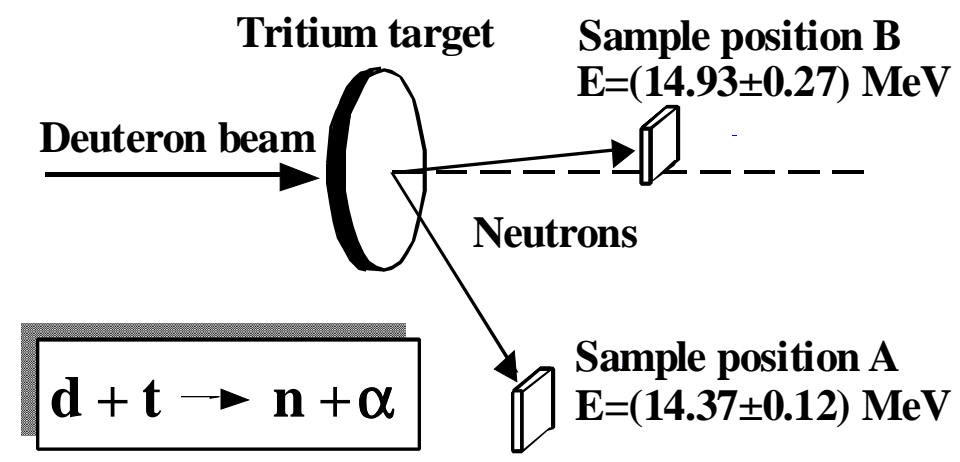

Figure 5. Geometry for the irradiation of the samples. A change of the sample position results in a small variation of the incidence neutron energy

For planning the experiment a calculation with the European Activation System (EASY) was carried out, assuming that $\mathrm{W}$ was irradiated at power plant conditions, this means with a 14 $\mathrm{MeV}$ neutron flux corresponding to a power density of $1 \mathrm{MW} / \mathrm{m}^{2}$, for a period of one year. The total contact dose rate of $\mathrm{W}$ as a function of time after the irradiation is shown in Fig.6 together with those of the nuclides mainly contributing. With a short irradiation of $10 \mathrm{~min}$ only, where a neutron fluence of $6.20 \cdot 10^{12} \mathrm{~cm}^{-2}$ was applied, and $\gamma$-spectra were measured at decay times from $3 \mathrm{~min}$ to $23 \mathrm{~h}$, and with a longer irradiation of $13.93 \mathrm{~h}$, where a neutron fluence of $2.32 \cdot 10^{14} \mathrm{~cm}^{-}$ ${ }^{2}$ was applied, and $\gamma$-spectra were measured at decay times from $30 \mathrm{~h}$ to $295 \mathrm{~d}$, all the activities that are dominant in $\mathrm{W}$ at fusion reactor conditions, could experimentally be determined.

The results are included in Table 1 and are compared with the corresponding calculated values, using EASY, the ITER reference design tool for activation calculations. The ratios of calculated-to-experimental activity show significant overestimations $(\mathrm{C} / \mathrm{E}=1.3-1.6)$ for most of the activities, if the version EASY-2001 is used. The reactions producing the activity are of the type (n, charged particle). As the Coulomb barrier for these charged particles is very high for nuclei with such atomic numbers as in the case of $\mathrm{W}$, they are emitted in the pre-equilibrium stage of the reaction. Detailed analyses of the reaction models [11] and a continuous validation process of the EASY library data with inclusion of recent differential and integral data [12] leads to better values for C/E as shown in Table 1 for EASY-2003. 


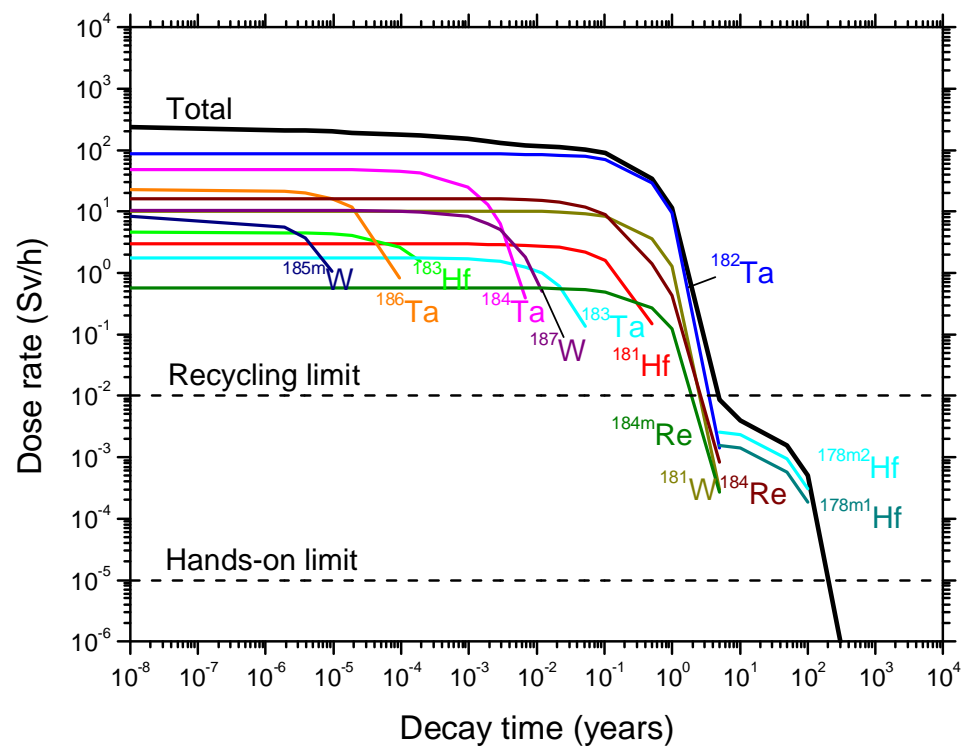

Figure 6. Total contact dose rate and dose rates and contribution from the nuclides indicated after irradiation of pure $\mathrm{W}$ at fusion power plant conditions as a function of time after irradiation.

Table 1: Nuclides for which the induced activity was measured, their half-life and the $\gamma$-radiation used to determine the activities, the experimental uncertainties, the ratios of calculated-to-experimental activity (C/E) obtained with EASY-2001 and EASY-2003, and the neutron reactions producing the activities. The upper part is for sample position B the lower one for sample position A (Fig. 5).

\begin{tabular}{|c|c|c|c|c|c|c|c|}
\hline Nuclide & $\begin{array}{l}\text { Half- } \\
\text { life }\end{array}$ & $\begin{array}{c}\mathrm{E}_{\gamma} \\
(\mathrm{keV}\end{array}$ & $\begin{array}{c}\Delta \mathrm{E} / \mathrm{E} \\
(\%)\end{array}$ & $\begin{array}{c}\text { C/E } \\
\text { EASY- } \\
2001\end{array}$ & $\begin{array}{c}\text { C/E } \\
\text { EASY- } \\
2003\end{array}$ & \multicolumn{2}{|c|}{$\begin{array}{c}\text { Reaction } \\
\text { Contribution (\%) }\end{array}$} \\
\hline${ }^{181} \mathrm{Hf}$ & $42.4 \mathrm{~d}$ & 482 & 7.5 & 1.66 & 1.29 & ${ }^{184} \mathrm{~W}(\mathrm{n}, \alpha)$ & 100 \\
\hline${ }^{183} \mathrm{Hf}$ & $64 \mathrm{~min}$ & $\begin{array}{l}459 \\
784\end{array}$ & 15. & 1.33 & 0.89 & ${ }^{186} \mathrm{~W}(\mathrm{n}, \alpha)$ & 100 \\
\hline${ }^{182} \mathrm{Ta}$ & $114.7 \mathrm{~d}$ & $\begin{array}{l}1121 \\
1189\end{array}$ & 6.8 & 1.60 & 1.26 & $\begin{array}{l}{ }^{182} \mathrm{~W}(\mathrm{n}, \mathrm{p}) \\
{ }^{183} \mathrm{~W}(\mathrm{n}, \mathrm{d})\end{array}$ & $\begin{array}{r}86.5 \\
6.5\end{array}$ \\
\hline${ }^{183} \mathrm{Ta}$ & $5.09 \mathrm{~d}$ & 354 & 7.8 & 1.36 & 1.29 & $\begin{array}{l}{ }^{183} \mathrm{~W}(\mathrm{n}, \mathrm{p}) \\
{ }^{184} \mathrm{~W}(\mathrm{n}, \mathrm{d})\end{array}$ & $\begin{array}{l}64.0 \\
20.7\end{array}$ \\
\hline${ }^{184} \mathrm{Ta}$ & $8.7 \mathrm{~h}$ & $\begin{array}{l}253 \\
318 \\
414 \\
921\end{array}$ & 6.5 & 1.34 & 1.17 & $\begin{array}{l}{ }^{186} \mathrm{~W}(\mathrm{n}, \alpha) \beta^{-} \\
{ }^{184} \mathrm{~W}(\mathrm{n}, \mathrm{p}) \\
{ }^{186} \mathrm{~W}(\mathrm{n}, \mathrm{t})\end{array}$ & $\begin{array}{r}15.3 \\
98.0 \\
2.0\end{array}$ \\
\hline
\end{tabular}




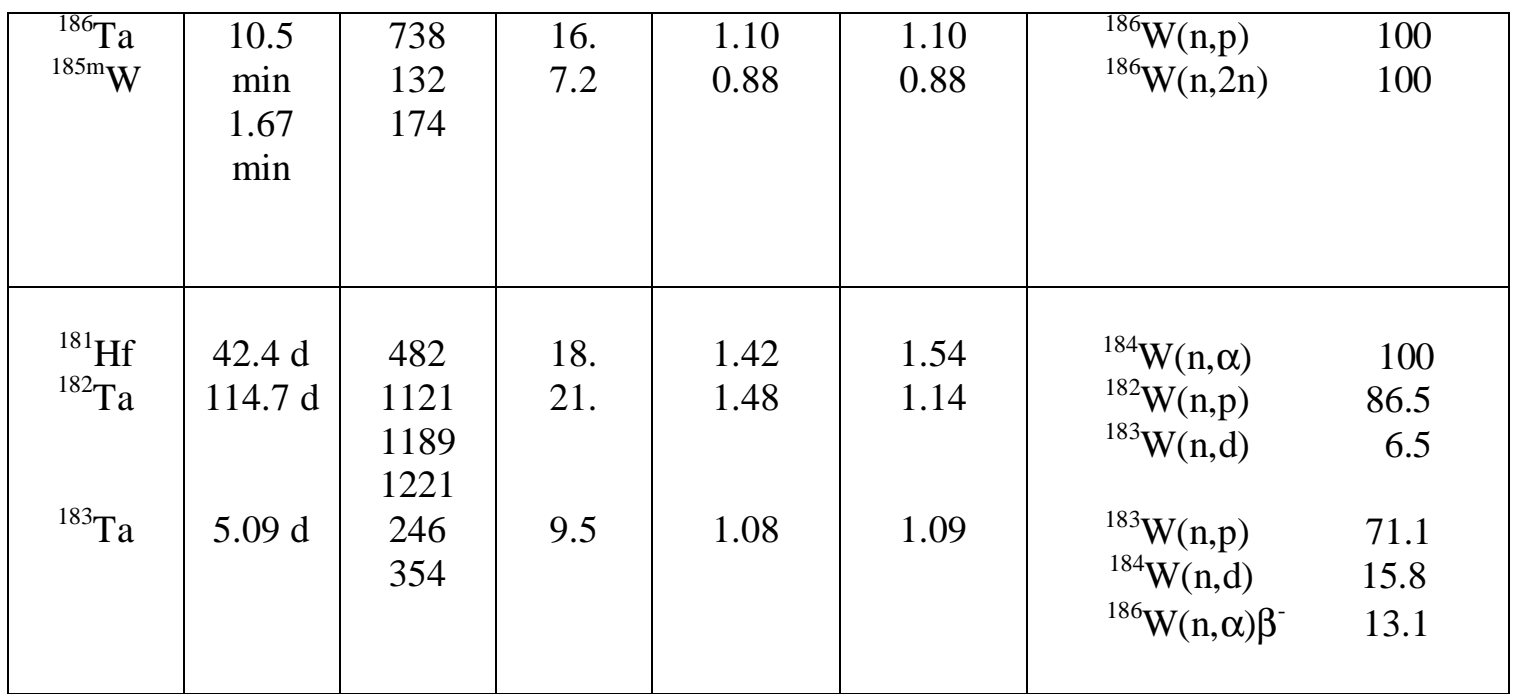

Similar activation data benchmarks were carried out for the ITER structural steel and vanadium alloys [13], for the reduced activation steel EUROFER [14], for $\mathrm{SiC}$ and $\mathrm{Li}_{4} \mathrm{SiO}_{4}$ [15] for $\mathrm{CuCrZr}$ [16] and for $\mathrm{Y}$ and $\mathrm{Pb}$ [17] as well.

\section{Test blanket module mock-up experiment}

The ITER partners are developing modules for tritium breeding to be tested in the second phase of the ITER experiments. The neutronics performance of the EU Helium-Cooled PebbleBed blanket module was investigated by a mock-up experiment. The main objective of measurements was the validation of the tritium production rate and of the shielding capability (that is reduced compared to a bulk shield) as predicted by the design tools of the module.

The mock-up is outlined in Fig. 7. In the main block, close to the $14 \mathrm{MeV}$ neutron source, two layers of the breeder material $\mathrm{Li}_{2} \mathrm{CO}_{3}\left(\mathrm{Li}_{2} \mathrm{SiO}_{4}\right.$ pebbles in the test blanket module) are arranged, in which stacks of probes were inserted at positions 1-8. The tritium produced in the probes was measured by $\beta$-counting in liquid scintillator after chemical preparation of the irradiated pellets [18]. The neutron and $\gamma$-ray flux spectra were measured at positions P1 and P2 of the rear block. 


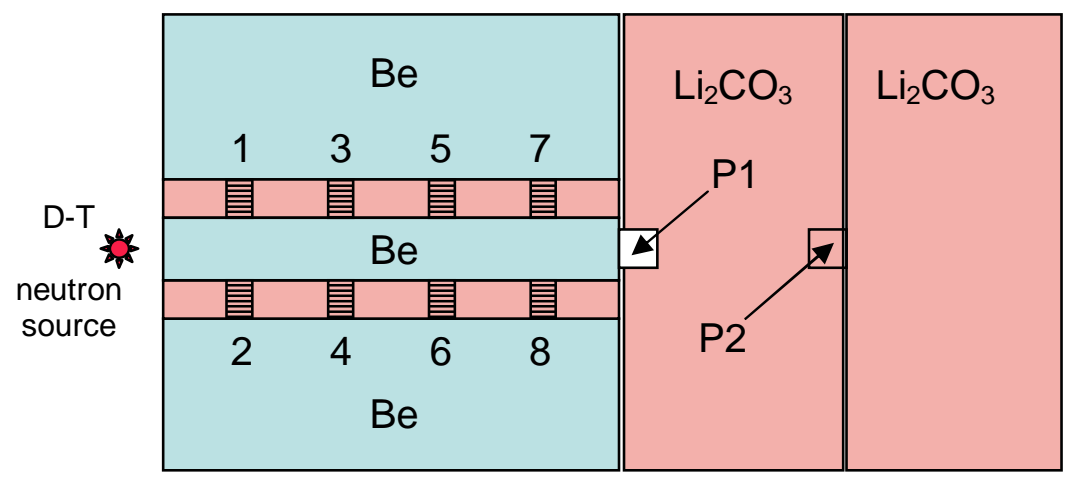

Figure 7. Vertical section through the mock-up assembly. The thickness was $60 \mathrm{~cm}$, height and width were about $30 \mathrm{~cm}$.

As an example, the measured tritium activities for stack 7 are presented in Fig. 8. The corresponding values calculated with the MCNP code and data of the library FENDL-2 are at $0.9-1.0$ of the experimental results. The tendency of a small underestimation of the tritium production of about $10 \%$ by the design tools was also found for the other probe stacks.

The fast neutron and the $\gamma$-ray flux spectra were measured with NE 213 spectrometer as in the bulk shield experiment. But in a breeding assembly the slow neutrons are of particular importance. In order to gain spectral information on the flux of these neutrons, the method of time-of-arrival (TOA) spectroscopy was applied. The TUD neutron generator was operated in pulsed mode (rectangular pulses of $10 \mu \mathrm{s}$ width and $1 \mathrm{kHz}$ repetition rate), and the neutrons arriving at $\mathrm{P} 1$ or $\mathrm{P} 2$ were counted with a ${ }^{3} \mathrm{He}$ proportional detector as function of time after the source pulse. By the slowing-down of the fast neutrons after the pulse, the TOA can be attributed to the mean neutron energy at this time. This period is followed by a time region where the epithermal neutrons are absorbed, mainly by ${ }^{6} \mathrm{Li}$. A comparison of measured and calculated detector count rate is presented in Fig. 9. In the TOA range $t>50 \mu \mathrm{s}$, which is used for analyses, the calculated count rate is about $10 \%$ lower than the measured one, as in the case of the tritium production. A detailed analysis, including the measurements at all positions and reaction rates determined with foil activation is in progress. 


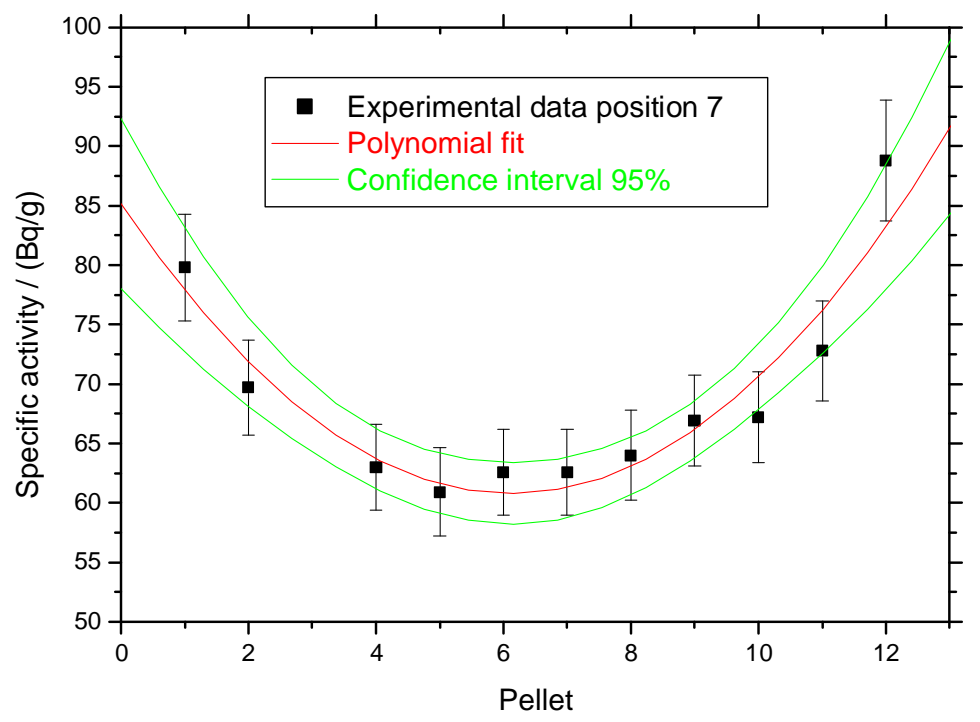

Figure 8. Measured tritium activities of the probe stack 7 pellets.

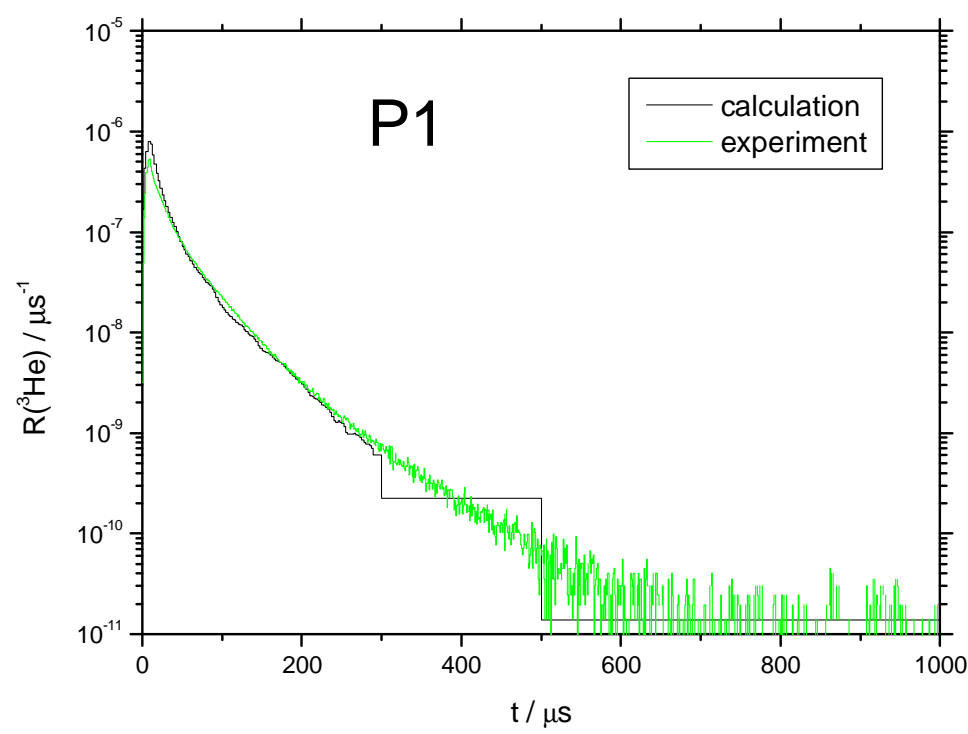

Figure 9. Comparison of measured and calculated $\quad{ }^{3} \mathrm{He}(\mathrm{n}, \mathrm{p})$ count rate as a function of the time after the neutron source pulse of $10 \mu \mathrm{s}$ width, normalized to one source neutron. 


\section{Outlook}

Experiments on neutronics mock-ups of fusion reactor components contribute to the validation of the nuclear design. They are useful also in future for major developments, such as the EU Helium-Cooled Lithium-Lead test blanket module.

The development of advanced materials for the fusion technology will result in requests for testing their data in benchmark experiments.

Whereas these experiments are carried out with neutrons of energies $\mathrm{E}<15 \mathrm{MeV}$, in most cases at D-T generators, a challenge arises with the design of the International Fusion Material Irradiation Facility the continuous neutron spectrum of which has the high-energy end at $\mathrm{E}=55$ $\mathrm{MeV}$, and nuclear data measurements and testing are strongly requested for the energy range 15 $\mathrm{MeV}<\mathrm{E}<55 \mathrm{MeV}[19]$.

\section{References}

[1] R. Aymar, Fus. Eng. Des. 55 (2001) 107.

[2] P. Batistoni, M. Angelone, U. Fischer, H. Freiesleben, W. Hansen, M. Pillon, L. Petrizzi, D. Richter, K. Seidel and S. Unholzer, Fus. Eng. Des. 47 (1999) 25.

[3] S. Guldbakke, H. Klein, A. Meister, J. Pulpan, U. Scheler, M. Tichy and S. Unholzer, ASTM STP 1228, American Society for Testing Materials, Philadelphia, 1995.

[4] P. Batistoni, Int. Workshop Fast Neutron Physics, TU Dresden, 5-7 September, 2002.

[5] K. Seidel, M. Angelone, P. Batistoni, U. Fischer, H. Freiesleben, W. Hansen, M. Pillon, D. Richter and S. Unholzer, Fus. Eng. Des. 51-52 (2000) 855.

[6] K. Seidel, Y. Chen, U. Fischer, H. Freiesleben, D. Richter and S. Unholzer, Fus. Eng. Des. 63-64 (2002) 211.

[7] K. Seidel, R. Eichin, U. Fischer, R.A. Forrest, H. Freiesleben, D. Leichtle, C. Negoita, and S. Unholzer, Fus. Eng. Des.81 (2006) 1211.

[8] H. Freiesleben, W. Hansen, D. Richter, K. Seidel and S. Unholzer, Fus. Eng. Des. 37 (1997) 31.

[9] K. Seidel, M. Angelone, P. Batistoni, Y. Chen, U. Fischer, H. Freiesleben, C. Negoita, R.L. Perel, M. Pillon and S. Unholzer, Fus. Eng. Des. 69 (2003) 379.

[10] K. Seidel, R. Eichin, R.A. Forrest, H. Freiesleben, S.A. Goncharov, V. D. Kovalchuk, D.V. Markovskij, D.V. Maximov and S. Unholzer, J. Nucl. Mater. 329-333 (2004) 1629.

[11] V. Avrigeanu, S.V. Chuvaev, R. Eichin, A.A. Filatenkov, R.A. Forrest, H. Freiesleben, M. Herman, A.J. Koning and K. Seidel, Nucl. Phys. A 765 (2006) 1.

[12] R.A. Forrest, M. Pillon, U. von Moellendorff and K. Seidel, Fus. Eng. Des. 63-64 (2002) 295.

[13] D. Richter, R.A. Forrest, H. Freiesleben, Va.D. Kovalchuk, Vi.D. Kovalchuk, D.V. Markovskij, K. Seidel, V.I. Tereshkin and S. Unholzer, J. Nucl. Mater. 283-287 (2000) 1434.

[14] K. Seidel, R.A. Forrest, H. Freiesleben, V.D. Kovalchuk, D.V. Markovskij, D.V. Maximov and S. Unholzer, J. Nucl. Mater. 307-311 (2002) 1037.

[15] K. Seidel, R.A. Forrest, H. Freieslebn, V.D. Kovalchuk, D.V. Markovskij, D. Richter, V.I. Tereshkin and S. Unholzer, Fus. Eng. Des. 58-59 (2001) 585.

[16] R. Eichin, C. Adelhelm, A.I. Blokchin, R.A. Forrest, H. Freiesleben, V.D. Kovalchuk, D.V. Markovskij, K. Seidel and S. Unholzer, J. Nucl. Mater. 329-333 (2004) 1638. 
[17] K. Seidel, R. Eichin, R.A. Forrest, H. Freiesleben and S. Unholzer, Fus. Eng. Des. 75-79 (2005) 969.

[18] P. Batistoni, M. Angelone, P. Carconi, K. Ochiai, I. Schaefer, K. Seidel, Y. Verzilov, G. Zappa and M. Pillon, Fus. Eng. Des. 75-79 (2005) 911.

[19] U. Fischer, P. Batistoni, E. Cheng, R.A. Forrest and T. Nishitani, Proc. Int. Conf. on Nuclear Data for Science and Technology, Sept. 26-Oct. 1, 2004, Santa Fe (USA); AIP Conf. Proc. Vol. 769, Melville N. Y. 2005, p. 1478. 